\title{
Application of VR Virtual Reality in Navigation Teaching
}

\author{
Bi Yanliang, Zhao Zhiqiang \\ Binzhou Polytechnic, Ocean, Department, Binzhou Shandong 256603, China
}

Keywords: virtual reality; navigation; practical teaching

Abstract: This paper discusses the various factors that restrict the quality of training in maritime practice teaching, analyzes the technical characteristics of virtual reality technology, and the various advantages of virtual reality technology applied in maritime practice teaching, and on the virtual practice training system. The development process is described. The application of virtual reality technology in the practical teaching of navigation can further improve the quality of practical teaching of navigation students.

\section{Introduction}

The Manila Amendment to the STCW Convention, which came into effect on January 1, 2012, and the Rules of the People's Republic of China Sea Boat Crew's Qualification Examination and Certification (abbreviated as 11 rules), which were implemented on March 1, 2012, are professional qualifications for sea-going crew members. The standard puts forward higher requirements. The Manila Amendment to the STCW Convention further emphasizes close-knit practice and emphasis on practical assessment and on-board training. With the development of ships in the direction of large-scale, rapid, specialized, and modernized, there will be more and more ship auxiliary equipment, more and more advanced, and the practice requirements for seafarers will inevitably become higher and higher. Seafarers and crew members must not only master the professional theoretical knowledge stipulated in the Convention, but also be able to master the prescribed ship equipment, be able to eliminate various faults, and be able to properly disassemble and install the ship equipment. In order to improve the quality of marine equipment operation teaching, these highly practical subjects have great challenges for maritime students and maritime schools without practical experience in real ships. The traditional practice teaching is affected by many factors, it is difficult to meet the requirements of the students' practical operation. Therefore, the introduction of virtual reality technology into the practice of maritime practice teaching can make up for the shortcomings of traditional practice teaching.

\section{Current status of practical teaching}

At present, many maritime colleges in China have set up practical courses for ship equipment, and all have equipment and venues for ship equipment operation practice. In the process of practical teaching, the actual operation of students can be enhanced to affect the improvement of the quality of practice teaching. There are several factors that influence it. 


\subsection{Limitations of practical teaching resources}

Practical teaching requires sufficient equipment for students to carry out operational training, and sufficient faculty to provide full guidance on the spot. Although the maritime schools have their own ship equipment and venues in accordance with the requirements of maritime schools, with the increase in the number of enrolled students, the number of sets of equipment is obviously insufficient. At the same time, due to limited investment in the later period, the equipment is improperly maintained, aged and Various conditions such as fault damage, equipment required for new requirements, and so on, exacerbate the state of equipment shortage[1].

\subsection{Limitations of practical teaching content}

In the practice teaching process, it is generally the operation requirements under the normal working conditions of the equipment taught by the instructor, and the student training is also the operation requirement under normal working conditions. For the performance of the equipment in the fault state and the solution, there may be damage to the equipment and personal injury. It is impossible to operate in the practice link. The limitation of the content of the practice link limits the scope of teaching to a part of the content.

\subsection{Limitation of practical teaching time}

In the practice teaching session, students can only operate on the real machine if they are taught and supervised by the instructor within the prescribed class hours, and at most, they can only guarantee that each student has several real machine opportunities. . Because of the short operation practice, the interval between practice learning and practice assessment is long, which makes many students still have a fuzzy state of operation after the class. The limitations of practical teaching in time also have an impact on students' practical teaching[2].

\subsection{Limitations of practical teaching safety}

Ship equipment is all electrical equipment, and the power is very large. Any mistakes in the operation may cause equipment damage or personal injury. The general ship equipment is expensive. Once it is damaged, it requires a large amount of maintenance, and it will also affect the actual operation training of other follow-up personnel. At the same time, the equipment failure will cause unexpected damage to the operator, so the actual operation process of the equipment Instructors must be on the scene to ensure the safety of the entire practical teaching process[3].

It can be seen from the above analysis that the current practice teaching is subject to various restrictions and constraints, as well as reasonable components. In order to further improve and improve the effectiveness and quality of maritime students' practical teaching, we can consider establishing a virtual ship equipment practical training system. Through computer virtual reality technology, the establishment of virtual ship equipment training venues, without the need to purchase and repair expensive products in the real world, students can operate the equipment in the virtual training ground according to the prescribed regulations, set various fault conditions for the equipment, let the students Virtual troubleshooting; establish a virtual disassembly process, understand the assembly process of the internal structure of the device; reasonably plan your own learning time, verify the learning effect through the system's assessment function; can be repeated training, regardless of time and space constraints. Increase the time for students to operate in practice, improve students' practical skills, and further improve the quality of seafarers' crew training[4]. 


\section{Characteristics of virtual reality technology}

Virtual reality technology is a highly human-computer interaction technology that can simulate human beings' visual, auditory and dynamic behaviors in the natural environment. It has a wide range of simulations in the field of simulation with its unique immersive, interactive and conceiving features. application. Virtual reality technology, through the use of computers to build virtual environments, to produce realistic sensory worlds such as three-dimensional vision, hearing and touch, with hardware devices, interactive observations with the objects of the virtual world, can effectively simulate the behavior of people in the natural environment, users Have a full sense of participation and experience. The virtual reality error reduction trend is as follows.

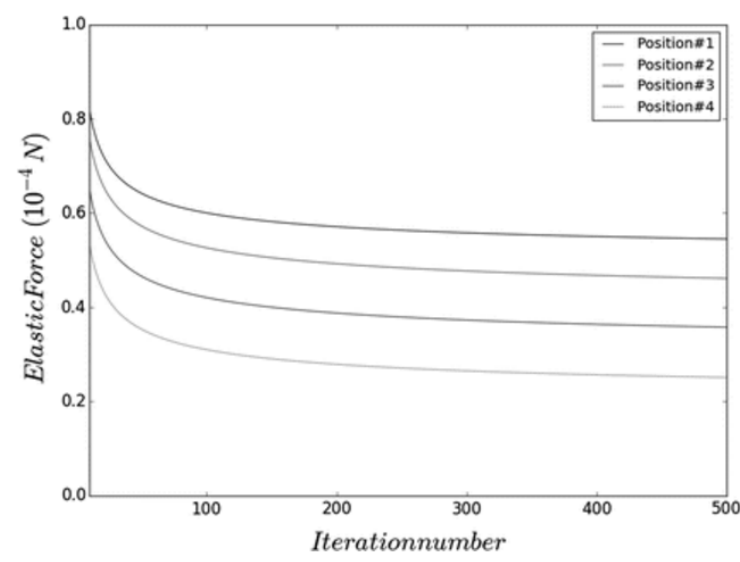

Figure 1: Virtual reality error reduction trend.

At present, there are many development tools for virtual reality systems on the market, and each development product has a common interactive function, and each has its own advantages. The more common development tools are the following.

VRP, a virtual reality development software independently developed by China. The software is simple to operate and low in cost. It breaks the monopoly of foreign virtual reality software and has a very high cost performance in China.

Quest-3D is a virtual reality product produced in the Netherlands. It has powerful functions, good rendering effect, support force feedback device, and has real physics engine and artificial intelligence database.

EON.Studio is a virtual reality product produced in the United States. It is a multi-purpose 3D/VR content integration production suite suitable for industrial, commercial, academic and military units. It can realize various complex and multi-dimensional interactions by writing $\mathrm{C}++$ program code to write interactive action programs. .

UNITY3D is the most user-friendly virtual reality development software produced in Denmark. It can easily create interactive content such as games, virtual roaming, virtual display, etc., and can publish the developed works into different platform formats, such as Andrio, Mac and windows. Wait.

VIRTOOLS (VT) is an engine developed by Dassault, France. Basic interactive development does not require programming. It only needs to connect the modules with specific functions according to certain operational logic to complete complex interactions. operating. When developing projects require more complex functions and the BB implementation is too complicated, VIRTOOLS provides the VSL scripting language and SDK development kit. 


\section{Virtual practice teaching system development process}

Generally, the virtual reality software itself does not have the modeling function. To build the virtual reality scene and the device model, it needs to be carried out in other special CAD software, and the virtual reality software completes the interactive operation of various programs. The general flow of the development of the virtual practice teaching and training system for maritime education is shown in the figure below. Virtual reality technology workflow as shown below.

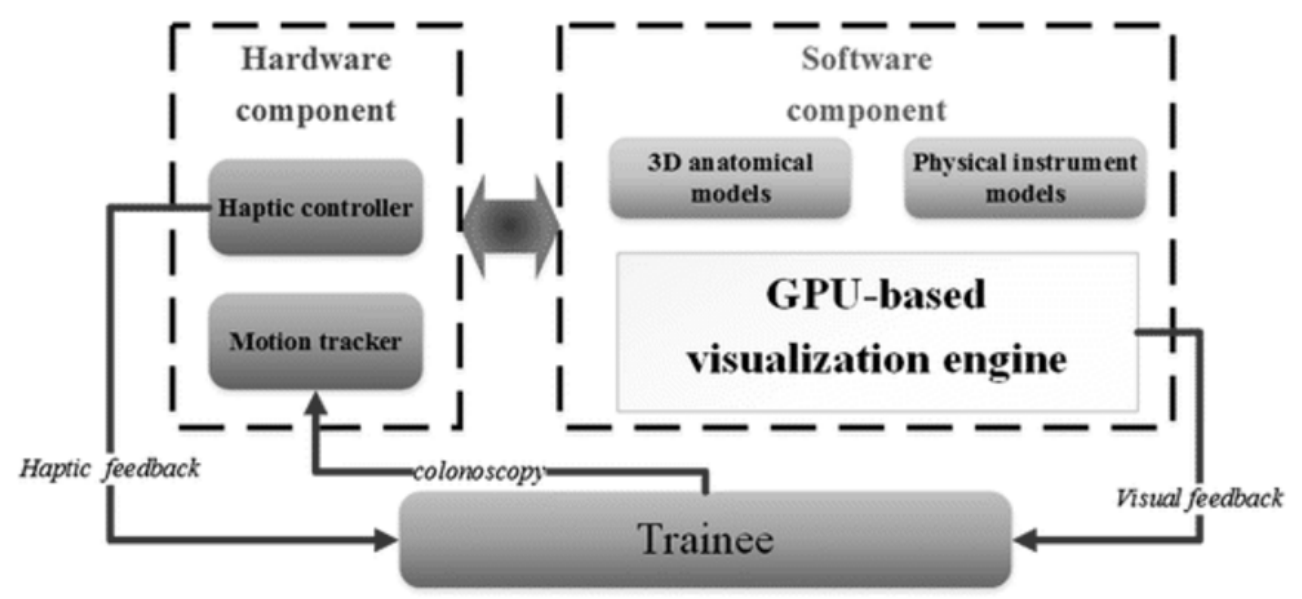

Figure 2: Virtual reality technology workflow.

CAD modeling: mainly through 3D solid modeling software (such as PROE, UG and SOLIDWORKS, etc.), according to the drawings of the ship equipment, complete the 3D graphics of each equipment part and the assembly model assembled from the parts.

Model optimization: The 3D model generated by CAD software can not be directly imported into the virtual reality software. The model needs to be optimized. The optimization process is completed by programs such as 3DSMAX or MAYA. The purpose of optimization is to generate 3D for CAD. The faces of the parts of the model are optimized, and various material textures are assigned to the parts to make the model more visually realistic.

Import the optimized model into the virtual reality development software environment, and program and function debugging through the software interactive development function. The practice teaching training system requires various interactive operations to realize the smoothness, liveness and fun of the virtual operation. Sex.

Publish the completed virtual reality practice training system into an installation system that can be run independently on a computer or network for the students to learn.

\section{Conclusions}

The current practice teaching of navigation is limited by many conditions. Students do not have sufficient time and opportunity to explore the equipment and have a certain impact on the effect of practical teaching. Applying virtual reality technology to the practical teaching field of navigation students, and developing a virtual ship equipment operation training platform, it can make up for all kinds of shortcomings in reality, enabling students to perform virtual disassembly training, virtual operation training and virtual troubleshooting for equipment. Training, etc., this training is not limited by time and space, is not limited by the expensive hardware resources and venues of real equipment, can expand the connotation of practical teaching, further enhance and improve the practical operation ability of maritime students, and train qualified for the world. International 
seafarers.

\section{References}

[1] Adetoun A. Oyelude. Virtual reality (VR) and augmented reality (AR) in libraries and museums[J]. Library Hi Tech News,2018,35(5).

[2] Li Benjamin J, Bailenson Jeremy N, Pines Adam, Greenleaf Walter J, Williams Leanne M. A Public Database of Immersive VR Videos with Corresponding Ratings of Arousal, Valence, and Correlations between Head Movements and Self Report Measures. [J]. Frontiers in psychology,2017,8.

[3] Ni Ding, Wen Zhou, Anthony Y.H. Fung. Emotional effect of cinematic VR compared with traditional $2 D$ film[J]. Telematics and Informatics,2018.

[4] Filip Grudzewski, Marcin Awdziej, Grzegorz Mazurek, Katarzyna Piotrowska. Virtual Reality in Marketing Communication - the Impact on the Message, Technology and Offer Perception - Empirical Study[J]. Economics and Business Review,2018,4(3). 